\title{
THE RHEUMATIC DISEASES
}

\section{FOREWORD}

By Sir WILlIAM WILlCOX, K.C.I.E., C.B., C.M.G., M.D., F.R.C.P., Chairman of the Executive Committee of the Empire Rheumatism Council.

THe appointment by the Royal College of Physicians in 1934 of the Special Committee on Chronic Rheumatic Diseases marked a great step forward in the campaign in this country against rheumatism in its many manifestations.

This Committee formed a link in the International League against Rheumatism, which was instituted in 1925, and its formation at the request of the International Council constituted the British Committee on Chronic Rheumatic Diseases.

With Sir Humphry Rolleston as chairman of the Committee of eighteen members, valuable advisory and consultative work was carried out.

A most important and tangible activity of the Committee has been the publication of the four Annual Reports for 1935, 1936, 1937 and 1938.

Dr. C. W. Buckley, as Editor of these Reports, has given the Committee the advantage of his vast knowledge and great clinical experience of a subject of great diversity and difficulty. In addition, he has devoted an enormous amount of time and personal attention to the selection and collection of suitable papers and abstracts. A review of the subject-matter of the four Annual Reports exhibits a collection of some of the most representative contributions to the recent advances in our knowledge of Chronic Rheumatic Diseases. They form a record of which the Committee may well be proud, and for which they are deeply indebted to Dr. C. W. Buckley for his unremitting care and successful efforts.

As a result of the national importance of the problems confronting it, the Committee on Chronic Rheumatic Diseases recommended to the Royal College of Physicians that the 
inauguration of an Empire Campaign against rheumatism, composed of lay and medical members, would be the most effective method of carrying out the objects which they had at heart.

On January 30, 1936, the Comitia of the Royal College of Physicians, with Lord Dawson of Penn in the chair, approved the proposal made by the Committee on Chronic Rheumatic Diseases that the existing Committee should act as the Scientific Advisory Committee to the major organisation to be set up for carrying out the work of the campaign, should it be so desired.

On February 7, 1936, the Empire Campaign against Rheumatism was inaugurated with Lord Horder as Chairman of the newly constituted body known as The Empire Rheumatism Council.

The Committee of the Royal College of Physicians was appointed the Scientific Advisory Committee of the Empire Rheumatism Council, this consisting entirely of medical members with power to add to their numbers.

Since that time the Empire Rheumatism Council has undergone great developments. H.R.H. The Duke of Gloucester has graciously accepted the office of President and important and influential committees have been established. Valuable schemes of research have been instituted, including the establishment of three important research fellowships and several travelling? scholarships. The Empire Rheumatism Council has given every encouragement to the institution of therapeutic research and the establishment and development of special clinics and hospitals for the treatment of rheumatic diseases.

Among the manifold developments of the Empire Rheumatism Council has been included the scientific work formerly carried out by the Committee of the Royal College of Physicians, the existence of which is not now necessary since it has been replaced by the Scientific Advisory Committee of the Council.

It is interesting to note that the wide developments of the Empire Rheumatism Council have brought home the fact that the link between acute rheumatism and chronic rheumatic diseases is much closer than was formerly recognised. It was often felt that the scope of the Committee of the Royal College of Physicians was hampered by the restriction of its field of work to "Chronic" Rheumatic Diseases. The Empire Rheumatism Council has found it necessary for its sphere of work to include all the rheumatic diseases, whether acute or chronic. 
It has for long been known that a special form of rheumatoid arthritis occurs in persons who have a history of acute rheumatism in childhood, with permanent cardiac changes as a result. There is strong evidence that a knowledge of the ætiology of acute rheumatism will go far to elucidate the causation of rheumatoid arthritis and the various forms of chronic rheumatic disease. Recent researches have shown that the morbid histological changes in rheumatoid arthritis and acute rheumatism possess great similarities. Also, the bacteriological evidence supports the view that the invading streptococci in the two conditions are closely related.

It must also be remembered that the prospects of success in the investigation of the ætiology of an acute febrile disease like acute rheumatism are much more clearly defined and hopeful than in the case of a chronic disease like chronic arthritis.

The Empire Rheumatism Council is actively engaged in the organisation of a scheme of research into the ætiology of acute rheumatism as it occurs in the naval training centres, and a special research fellowship has been established. with this object in view.

It will be of great interest to know that though the Annual Reports of the Committee of the Royal College of Physicians on Chronic Rheumatic Diseases will cease, their place will be taken by a new publication to be brought out under the ægis of the Scientific Advisory Committee of the Empire Rheumatism Council.

This new journal, under the title The Rheumatic Diseases, will be published about three times a year by Messrs. $\mathbf{H}$. K. Lewis and Co., who were so helpful in the publication of the excellent Annual Reports. It will be noted that the scope is wider than that of the former Annual Reports, since both acute and chronic forms of rheumatism are included.

Dr. C. W. Buckley has most kindly undertaken the editorship of the new publication, with the collaboration of Dr. W. S. C. Copeman and Mr. A. G. Timbrell Fisher, and this will ensure the maintenance of the high scientific standard which has characterised the former Annual Reports.

It is intended that the new journal shall consist entirely of original papers and reports, specially selected for their value and interest, with the exception that the Annual Report of the 
Empire Rheumatism Council will be bound up with it. The first number of the new journal contains interesting records of research into the type of organism responsible for the causation of acute forms of rheumatism.

Dr. Mervyn Gordon shows the part played by a virus in the causation of experimental fibrositis and arthritis. Dr. G. Hardy Eagles discusses with an open mind the possibility of a virus participating in the causation of acute rheumatism, and Dr. Dyson makes a preliminary Report on the same aspect. Dr. A. B. Stewart has a valuable paper on the hæmolytic streptococci of the upper respiratory tract and their relation to acute rheumatism.

The pathology of acute rheumatism and rheumatoid arthritis is dealt with in interesting contributions by Dr. Douglas $\mathbf{H}$. Collins and Mr. A. G. Timbrell Fisher. Dr. J. Barnes Burt publishes an interesting account of a case of Heberden's nodes in a girl 15 years of age.

Reviews of the recent publications of Dr. David M. Kling on "The Synovial Membrane and Synovial Fluid" and of Professor Ejnar Jarlov on "Focal Infection and Arthritis in the Light of Experiment" complete this issue. A second number will appear in May.

Dr. C. W. Buckley and his colleagues are to be congratulated on the new outlook comprehended in the first publication of The Rheumatic Diseases, and, in view of the great activity in so many departments of research into the many manifestations of rheumatic diseases, they may rest assured that they will find no lack of material for the publication of the subsequent numbers of this valuable journal. 